Z. Klin. Chem. Klin. Biochem.

11. Jg. 1973, S. $121-122$

\title{
Photometrische Bestimmung des Kupfers im Serum ohne Enteiweißung
}

\author{
Von Gerlinde Beyer und G. Hillmann
}

Aus dem Chemischen Institut (Vorstand: Prof. Dr. G. Hillmann) der Städtischen Krankenanstalten Nürnberg

(Eingegangen am 30. August/11. Dezember 1972)

\author{
Herrn Prof. Dr. Heinrich Dannenberg qum 60. Geburtstag gewidmet
}

Kupfer wird aus seiner Bindung an Coeruloplasmin durch $\mathrm{H}_{2} \mathrm{O}_{2}$ bei pH 5,5 in Gegenwart von Harnstoff und Hydroxypolyäthoxydodecan freigesetzt. Nach Reduktion mit Natriumascorbat wird der Kupfer (I)-Bathocuproinkomplex photometrisch gemessen.

\section{Photometric determination of copper in serum without deproteinization}

Copper was released from caeruloplasmin by treatment with $\mathrm{H}_{2} \mathrm{O}_{2}$ at $\mathrm{pH} 5.5$ in the presence of urea and hydroxypolyethoxydodecane. The copper (I) bathocuproin complex was measured photometrically after reduction with sodium ascorbate.

Alle bisher bekannten indirekten photometrischen Methoden zur Bestimmung von Kupfer im Serum mit spezifischen Komplexbildnern erfordern eine vorherige Spaltung der stabilen Kupfer-Eiweiß-Bindung durch Inkubation mit starken Säuren (1). Die photometrische Messung der Kupferkomplexe erfolgt nach Entfernung des Eiweißes durch Präzipitation oder Dialyse (2).

Die nachstehend beschriebene neue Methode beruht auf der Oxidation der kupferbindenden Eiweißgruppen durch $\mathrm{H}_{2} \mathrm{O}_{2}$ in Gegenwart eines nichtionischen Detergens (Hydroxypolyäthoxydodecan $=$ Thesit) und Harnstoff bei Raumtemperatur bzw. $50^{\circ} \mathrm{C}$. Die optimale $\mathrm{Zu}-$ sammensetzung des Spaltungsreagenzes wurde empirisch ermittelt. Wir fanden, daß durch Harnstoff und Thesit die Abspaltung des Kupfers beschleunigt und das Auftreten von Trübungen durch Lipide und präzipitierte Proteine verhindert wird. Gleichzeitig werden endogene Serumfarbstoffe oxidativ eliminiert. Für die Kupferbestimmung hat sich die Anwendung von Bathocuproindisulfonat nach Reduktion mit Ascorbinsäure als geeignet erwiesen. Versuche mit anderen Komplexbildnern für Kupfer wie Diäthyl-dithiocarbamat, Neocuproin, Cuprizon, Oxalyldihydrazid/Acetaldehyd, Dithizon, Diphenylcarbazid führten $\mathrm{zu}$ keinem brauchbaren Ergebnis. Die angegebene Methode ermöglicht eine geringere Probenverdünnung (1:1) als bei den üblichen Verfahren mit Eiweißfällung (1:2) und damit eine erhöhte Empfindlichkeit. Die Methode erfordert eine zusätzliche Messung der jeweiligen Serumblindwerte in Analogie zur Bestimmung des Serumeisens ohne Enteiweißung mit Bathophenantrolindisulfonsäure (3).

Die Vorteile unserer Methode bestehen

1. in der Vermeidung der Eiweißfällung

2. in der Anwendungsmöglichkeit für diskontinuierliche Mechanisierung
3. in der Anwendung für lipämische und hyperbilirubinämische Seren.

4. in der bereits genannten höheren Empfindlichkeit.

Mit dieser Methode wurden bisher 2000 Serum-Kupferbestimmungen störungsfrei durchgeführt.

\section{Reagenzien und Geräte}

Spektral- oder Spektrallinienphotometer.

Einwegröhrchen aus Kunststoff mit Stopfen (Fa. Sarstedt).

\section{Reagenzien}

1. primäres Nagtriumphosphat $\left(\mathrm{NaH}_{2} \mathrm{PO}_{4} \cdot \mathrm{H}_{2} \mathrm{O}\right.$ Merck 6346)

2. sekundäres Natriumphosphat $\left(\mathrm{Na}_{2} \mathrm{HPO}_{4} \cdot 2 \mathrm{H}_{2} \mathrm{O}\right.$ Merck 6580$)$.

3. Harnstoff (Merck 8487)

4. Thesit (Hydroxypolyäthoxydodecan Desitin-Werk Carl Klinke Hamburg)

5. Wasserstoffperoxid 30\% (Merck 7209)

6. Natriumascorbat (Merck 500076)

7. Bathocuproindisulfonsäure-Dinatriumsalz p. a. (Merck 1654)

8. Kupfersulfat $\left(\mathrm{CuSO}_{4} \cdot 5 \mathrm{H}_{2} \mathrm{O}\right.$ p. a. Merck 2790)

9. Salpetersäure konz. Dichte 1,4 p. a. (Merck 454).

\section{Lösungen}

I. $0,5 \mathrm{~mol} / \mathrm{l}$ Phosphatpuffer $\mathrm{pH} \mathrm{5,5}$

a) $0,5 \mathrm{~mol} / 1 \mathrm{NaH}_{2} \mathrm{PO}_{4}\left(69 \mathrm{~g} \mathrm{NaH} \mathrm{PO}_{4} \cdot \mathrm{H}_{2} \mathrm{O} / \mathrm{l}\right)$

b) $0,5 \mathrm{~mol} / 1 \mathrm{Na}_{2} \mathrm{HPO}_{4}\left(89 \mathrm{~g} \mathrm{Na} 2 \mathrm{HPO}_{4} \cdot 2 \mathrm{H}_{2} \mathrm{O} / \mathrm{l}\right)$.

Beide Lösungen werden im Verhältnis $100 \mathrm{ml}(\mathrm{Ia})+15 \mathrm{ml}(\mathrm{Ib})$ vermischt. Eine genaue Einstellung des $\mathrm{pH}$-Wertes mit der Glaselektrode ist nicht erforderlich.

\section{Spaltungsreagenz}

$100 \mathrm{ml}$ Phosphatpuffer $\mathrm{pH} 5,5$ werden mit $5 \mathrm{ml}$ Thesit und $50 \mathrm{~g}$ Harnstoff versetzt. Die Substanzen lösen sich leicht unter fließendem heißen Wasser. Nach dem Abkühlen der Lösung werden $21 \mathrm{ml}$ Wasserstoffperoxid zugesetzt. (Haltbarkeit des Spaltungsreagenzes bei Raumtemperatur etwa 2 Wochen.)

III. Natriumascorbatlösung $1 \mathrm{~mol} / 1$ in Wasser $(198 \mathrm{~g} / \mathrm{l})$.

Die erforderliche Menge wird jeweils frisch angesetzt. 
IV. Bathocuproindisulfonsäure-Dinatriumsalz $10 \mathrm{~g} / 1$ Wasser

V. Kupfer-Stammlösung

$0,392 \mathrm{~g} \mathrm{Kupfersulfat} \mathrm{werden} \mathrm{in} \mathrm{etwa} 50 \mathrm{ml}$ Wasser gelöst und $27 \mathrm{ml}$ konzentrierte Salpetersäure zugegeben. Auffüllen mit Wasser (bidest.) auf 1 Liter.

VI. Kupfer-Standardlösung

$5 \mathrm{ml}$ der Kupfer-Stammlösung werden mit Wasser auf $200 \mathrm{ml}$ verdünnt $\left(2500 \mu \mathrm{g} / \mathrm{l}\right.$ in $\left.0,01 \mathrm{~mol} / 1 \mathrm{HNO}_{3}\right)$.

\section{Durchführung der Bestimmung}

Bestimnungsansatz

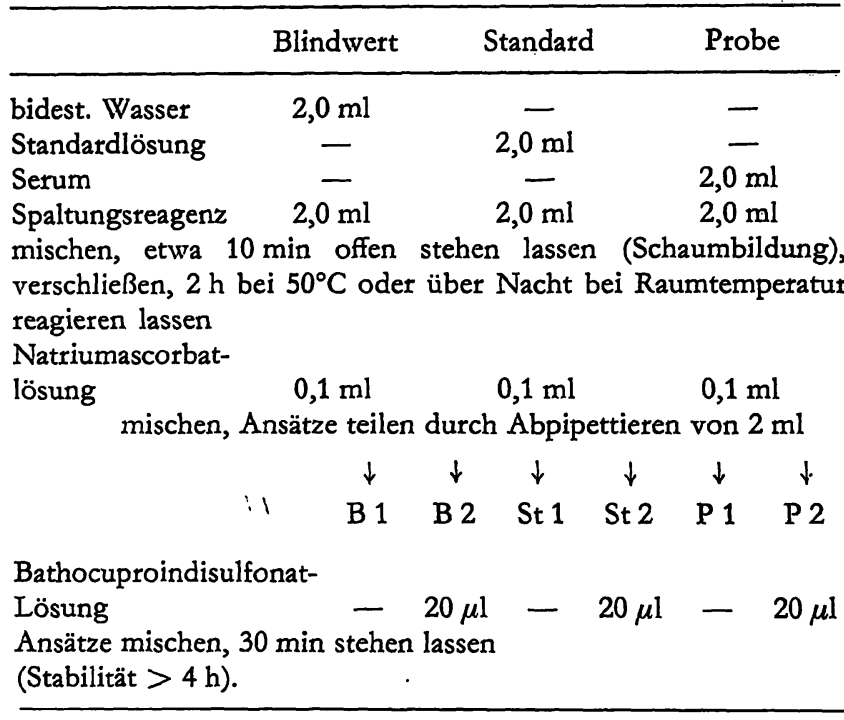

\section{Messung}

Wellenlänge $460-490 \mathrm{~nm}$ (492 nm bei Filterphotometern).
Glasküvette $1 \mathrm{~cm}$ Schichtdicke (Durchflußküvette). Messung Probe 1 gegen Blindwert 1.

Standard 2 und Probe 2 gegen Blindwert 2.

Berechnung: $\frac{(\text { Ext. Probe 2 }- \text { Ext. Probe 1) } 2500}{\text { Ext. Standard }}=\mu \mathrm{g} / 1$.

$\mu \mathrm{g} / \mathrm{l} \cdot 0,0157=\mu \mathrm{mol} / \mathrm{l}$

\section{Ergebnisse}

Präzision in der Serie $(\mathrm{N}=30)$.

Mittelwert $\overline{\mathrm{x}} 1265 \mu \mathrm{g} / \mathrm{l}$.

Standardabweichung $\mathrm{s} \pm 34,4 \mu \mathrm{g} / \mathrm{l}$.

Variationskoeffizient VK $=2,71 \%$.

Präzision von Tag qu Tag $(\mathrm{N}=50)$

Mittelwert $\bar{x} 1643 \mu \mathrm{g} / \mathrm{l}$.

Standardabweichung $\mathrm{s} \pm 61,3 \mu \mathrm{g} / \mathrm{l}$.

Variationskoeffizient $\mathrm{VK}=3,73 \%$.

\section{Richtigkeit}

Vergleichsbestimmungen mit Enteiweißung $(N=40$, Komplexbildner Bathocuproindisulfonat)

Korrelationskoeffizient $r=1,0019$,

Wiederfindungstate bei Zusatzversuchen $98 \%$.

\section{Arbeitszeit}

Pro Analyse $=1 \mathrm{~min}$ (manuelle Technik mit Durchflußküvette bei Serienbestimmungen).

Die Durchführung von Mikroanalysen unter Einsatz von $500 \mu \mathrm{l}$ Serum ist mit entsprechend reduzierten Ansätzen möglich, jedoch für Serienbestimmụngen mit Durchflußküvetten nicht geeignet.

\section{Literatur}

1. Hinsberg, K. \& Lang, K. (1957), Medizinische Chemie, 3. Aufl,, S. 38-41, Verlag Urban \& Schwarzenberg, München-Berlin-Wien. - 2. ZAK, B. (1958), Clin. Chim. Acta 3, 328-334. - Z Z AK, B. \& RessLeR, N. (1956), Anal. Chem. 28, 1158-1161. - Edan, K. (1962), Ärztl. Praxis 14, 1911-1912. FriedmanN, H. S. \& CheEk, C. S. (1971), Clin. Chim. Acta 31, 315-327. - Führ, J. \& Stary, E. (1970), Ätztl. Lab. 16, 244 bis 253 - Klein, B., Kleinmann, N. \& Searcy, R. L. (1970), Clin. Chem. 16, 495-499. - Leppla, W., Brokate, W. \& Keller, H. E. (1963), in Internat. Techn. Sympos. Automat. Analyt. Chemie, S. 225-229. - SCHMidt, R., Weis, W., KLINGMüLLER, V. \& Staudinger, H. J. (1967), diese Z. 5, 304-309. - Young, D. S. \& Hrcks, J. M. (1965), J. Clin. Pathol. 18, 98-102. - ZAK, B. \&
Epstein, E. (1964), in Internat. Techn. Sypms. Automat. Analyt. Chemie S. 485-492. - ZAK, B. \& Epsrern, E. (1965), Clin. Chem. 11, 641-644. - Summers, R. M. (1960), Anal. Chem. 32, 1903 bis 1904. - Kattermann, R. \& Köhring, B. (1971), diese Z. 9, 391-395. - KIEIN, B., LuCAS, L. B. \& SEARCY, R. L. (1969), Clin: Chim. Acta 26, 517-523. - KleIN, B., Weber, B. K., Lucas, L., Foreman, J. A. \& Searcy, R. L. (1969), Clin. Chim. Acta 26, 77-84. - BeAle, R. N. \& Croft, D. (1964), J. Clin. Pathol. 17, 260-263. - 3. Schade, A. L., Oyama, J., Reinhart, R. W. \& Mrller, J. R. (1954), Proc. Soc. Exp. Biol. Med. 87, 443-448. - FürHR, J. (1965), Med. Monatsschr. Stuttgart 19, 281-283.
Prof. Dr. G. Hillmann

Städt. Krankenanstalten Nürnberg Chemisches Institut

85 Nürnberg

Flurstraße 17 